\title{
The embeddedness of inclusionary housing in planning and housing systems: insights from an international comparison
}

\author{
George de Kam • Barrie Needham • Edwin Buitelaar
}

Published online: 19 June 2013

(C) Springer Science+Business Media Dordrecht 2013

This special issue is about a particular way in which a country, through its public policy, can stimulate the provision of social or affordable housing. ${ }^{1}$ This way has the following components:

- land is made available for building social housing, by reserving land especially for that use (and thus by protecting it from competition from other possible uses);

- that land is made available at prices below the unconstrained market price for such land in such locations;

- the land is made available in locations next to, or mixed with, land used for other purposes, so that the social housing which is built is not segregated but integrated with other uses, in particular with market-rate housing. Social housing is thus an element of development projects which contain a mix of uses.

- the costs of making that land available, possible some of the costs also of building the housing, will usually be subsidised out of the development gains arising from the whole development project.

\footnotetext{
${ }^{1}$ Since the use of the adjective 'social' or 'affordable' is context-specific, we will use both words interchangeably.
}

G. de Kam (ه)

Spatial Planning, Radboud University Nijmegen, P.O. Box 9108, 6500 HK Nijmegen, The Netherlands e-mail: g.dekam@fm.ru.nl

B. Needham

Spatial Planning, Radboud University Nijmegen, Nijmegen, The Netherlands

e-mail: needham@xs4all.nl

E. Buitelaar

PBL Netherlands Environmental Assessment Agency, P.O. Box 30314, 2500 GH The Hague,

The Netherlands

e-mail: Edwin.Buitelaar@pbl.nl

E. Buitelaar

Amsterdam School of Real Estate, P.O. Box 140, 1000 AC Amsterdam, The Netherlands 
This practice has three particular properties which distinguish it from many other ways of providing social housing:

- there are stake holders involved in the provision of social housing besides public or semi-public bodies;

- not all of the (net) costs are paid out of public funds, but out of commercial profits;

- the land-use planning system is applied in a particular way in order to make this possible.

When this way of stimulating the provision of social housing is employed, we call it for the purposes of this article 'inclusionary housing'. Note that this term includes more than some other definitions of inclusionary housing, such as that used in the recent book on this subject by (Calavita and Mallach 2009: 15), namely: "land use regulations that require developers of market-rate residential development to set aside a small portion of their units, usually between 10 and $20 \%$, for households unable to afford housing in the open market. Alternatively, they can choose to pay a fee or donate land in lieu of providing units." That definition, which is specific to the American practice called 'inclusionary zoning', describes a response to social-economic and ethnic segregation, which emerged in the US of the 1970s. Today, versions of this approach are to be found in many other countries such as the UK, Ireland, The Netherlands, France, Italy, Spain, India, SouthAfrica, Israel, New Zealand, Canada and Australia (see also Calavita and Mallach 2010).)

It will be seen that the definition used by Calavita and Mallach describes a practice which is just one form - albeit an important and fairly common form-of inclusionary housing according to the definition put forward in this chapter. Some of the practices described in this special issue fall within the definition of Calavita and Mallach, others do not: but they are all examples of inclusionary housing according to the wider definition.

There is an increasing literature that reports on how different forms of inclusionary housing work and what their results are in terms of housing production for low-income groups (Mallach 1984; Calavita et al. 1997; Calavita and Grimes 1998; Williams 2000; Monk et al. 2007; Monk and Whitehead 2010; Calavita and Mallach 2010; Buitelaar and De Kam 2012). Particularly worth mentioning here is the comprehensive book by Calavita and Mallach (2010). It offers various concepts for framing research on inclusionary housing, and it gives a wide array of examples from different countries from all continents. This special issue takes the discussion further. It does this first by conceptualising, and theorising about, the factors that lie behind the emergence, design and use of inclusionary housing. We are especially interested in how and to what extent inclusionary housing is institutionally and culturally embedded. Related to this, and arising out of it, the second aim of this special issue is better to understand the country-specific differences in inclusionary housing policies. A third aim arises from the fact that in many countries the market situation has changed since the publication of the book by Calavita and Mallach: depressed profits in the development industry seem to have strengthened its efforts legally to contest $\mathrm{IH}$ policies. So in this special issue, the economic aspects of inclusionary housing (viability and compensation) and the risks involved get especial attention.

With regard to the institutions to be considered, we follow Mallach and Calavita in emphasising that, for understanding the emergence of $\mathrm{IH}$ policies, it is essential to analyze changes in housing systems and in planning systems in combination. First, because planning designates the location and amount of new housing, and so may create land shortages (thus driving up prices) or hinder a flexible response to changing circumstances in the housing market. Second, because affordable housing that is provided through the planning system is always part of a broader set of instruments and policies in the housing 
system. And third because IH is a potential mechanism for land value recapture through the interplay of the planning system and the property rights regime (Calavita and Mallach 2010, p. 9-10).

Both systems-housing, planning-and the interaction between them have been described more or less extensively for the countries featuring in Calavita and Mallach (2010), but we want to explore what a more systematic classification of these systems (and their cultural and ideological backgrounds) adds to our understanding of the institutionalization of IH. We do this for a number of countries, which we can at this stage classify using the typology put forward by Calavita and Mallach:

- Countries that enable IH but do not require it: The UK, The Netherlands

- Countries that do not enable IH, let along mandate it, but where local initiatives for IH are emerging: Italy

- Countries which have reasons for not using IH: Norway, Turkey

- Countries with decentralized land use regulation and a variety of state or provincial legal and regulatory schemes, where $\mathrm{IH}$ can be practised and is being practised widely-some states in the US, in particular California-or where IH is being tentatively and locally introduced-Australia and New Zealand ${ }^{2}$

What is interesting, and puzzling at the same time, is that inclusionary housing is becoming widespread, and transcends boundaries between countries that seem to have quite different housing and planning traditions. For instance, both the US and the Netherlands, have adopted some form of inclusionary housing, while the first has a small and strongly marginalized public housing sector and the second has a large and encompassing one. This raises a question about what the common drivers are, but also where the specific designs of inclusionary housing differ. In order to understand this better, we apply a simple conceptual model of how inclusionary housing is embedded in the housing and planning systems. The most elementary version of this model is represented in Fig. 1. We distinguish between those factors which influence the wish to practice $\mathrm{IH}$, and the factors which influence the possibilities of introducing $\mathrm{IH}$. And we identify three such factors. One is the housing system, which determines how housing is provided, including any possible alternatives for IH. The second is the planning system, which (re)distributes property rights and defines the role of actors and planning procedures. The third arises out of a combination of the first two, namely the amount of any development surplus when housing is developed. Further on, this model will be elaborated in more detail.

From this perspective, this special issue lies at the heart of the relationship between planning and housing, two intimately linked social activities, but often researched on separate scholarly platforms. Housing and planning only occasionally come together in research, such as in the recent wave of publications in which high house prices and low housing supply elasticity are attributed to the stringency of land-use regulations (see e.g. Glaeser et al. 2005; Quigley and Raphael 2005), or in the research of 'boundary workers' such as Oxley (2004) who investigate the relationship systematically and consistently. Taking this perspective, we look at how and to what extent the emergence, design and use of inclusionary housing is embedded in housing and planning systems, and how it is influenced by the way these systems react to, or are adapted to, the current economic downturn.

\footnotetext{
2 This special issue contains nothing about the countries which mandate IH: Spain, Ireland.
} 

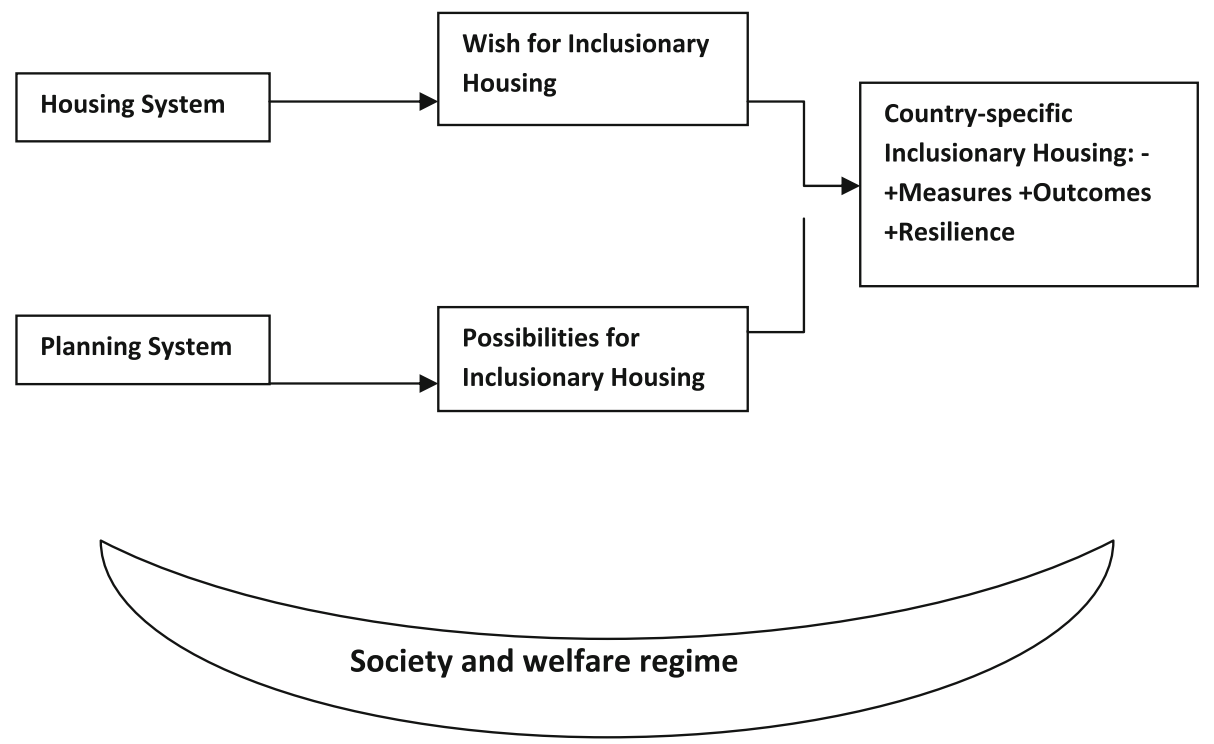

Fig. 1 Basic relations between the housing and planning system and inclusionary housing

Before elaborating our expectations about the relations between the elements of the conceptual model, we go more deeply into how housing and planning systems separately might influence IH.

\section{Housing systems}

There can be many reasons for introducing inclusionary housing, such as concentrations of poverty or excluded groups and changing relations between the public and private sector. But what all initiatives have in common is the concern with the affordability of housing and the problems with providing affordable housing. Linked to affordability are issues about ensuring the availability of land and finance and, in many cases, the wish to support mixed communities.

Affordability has always been a key concern of housing research, both analyticallyhow is affordable housing delivered?-as well as normatively or prescriptively-how much affordable housing should be provided and how? Underlying this issue are additional questions about the affordability of 'market housing' on the one hand (often seen as being exacerbated by planning controls) and questions about affordable housing as targeted programmes aiming to provide for those unable to access market housing.

Even though some have argued that much housing research is a-theoretical (Kemeny 2001), a significant and theoretically strongly grounded body of knowledge on the provision of housing and the importance of institutions has developed over the years (Ball 1983, 1998; Bengtsson and Ruonavaara 2010; Needham 2012). Particularly apt for this special issue is the comparative work on housing institutions (e.g. Kemeny 2001; Harloe 1995; Blessing 2012).

Taking the work of Esping-Andersen (1990) on welfare regimes as a starting point, Kemeny has developed a typology of (social) housing systems in order to position different 
countries. In the work of welfare researchers, housing is one of the four pillars of the welfare state, although the least researched and the most wobbly, according to Kemeny (2001). The others are social security, health and education. Esping-Andersen identifies three different types of welfare regimes that are derived from society's power structures and inter-class relationships. There are social-democratic, corporatist and liberal regimes. These regimes have led to welfare systems, which can be seen as the tangible reflection of the regimes: de-commodified, conservative and residual systems, respectively.

Social-democratic regimes are regimes in which working-class movements have been able to gain hegemony at the expense of conservative forces. As a result, the pillars of the welfare state became decommodified, in the sense that they are regarded as social responsibilities rather than goods (commodities) that are to be traded on the market. Corporatist regimes are regimes where no subgroup within society has hegemony. Each group has its own subsystem for the provision of welfare services, and this may lead to a wide-ranging supply, similar to that in social-democratic systems, but provided largely by non-profit organisations rather than by the state (Salamon and Lester 1997) The liberal regime is the opposite of the social-democratic regime: conservative forces have hegemony over working-class groups. These conservative forces try to target welfare provision as much as possible by making the system needs-based.

Kemeny (2001) has translated this typology into one for housing systems. He makes a distinction between unitary rental systems and dualist rental systems. Harloe (1995) makes a similar distinction; he differentiates between social housing consumption in the form of the mass model characterised by broad access, and the residual model, limited to those deemed in need (Harloe 1995).

The dualist system, or residual model, can be found in countries with mainly liberal regimes. In these systems the state takes direct responsibility for the provision of housing for those in need, in a 'public' command-economy sector. This sector exists in company with a private market. States that adhere to this type of regime try to keep the two types of tenure separate. In addition, most of these countries have a fairly large market for owneroccupied housing. According to Kemeny, English-speaking countries, most Mediterranean and some Scandinavian countries (Norway, Finland and Iceland) represent this system.

The unitary rental system, or mass model, exist in countries with corporatist or socialdemocratic systems. In these countries, it is often not the state that provides social or affordable housing, but hybrid organisations that cross the boundaries between public and private. In addition, the state encourages (or at least does not discourage) these not-forprofit organisations not to limit themselves to households in need, but to include middleincome groups as well. Because of that, and the privileges that not-for-profits sometimes get, they are in competition with the for-profits in the private rental market. Countries that are part of this family are for instance The Netherlands, Germany, Sweden and Denmark. It needs to be noted that there is now pressure on unitary regimes from the E.U. rules on competition and state-aid to adapt to dualist institutional requirements (Blessing 2012, p. 204).

As Hoekstra (2009) has shown, there is some empirical support for the validity of Kemeny's classification, while at the same time it is problematic to put countries like Germany or Ireland into it. ${ }^{3}$ Furthermore, Hoekstra found signs of convergence between the two types of housing systems. As we know, inclusionary housing includes the provision not only of social rented housing, but of affordable housing for ownership also. Therefore, for a thorough understanding of differences in inclusionary housing policies, a

\footnotetext{
${ }^{3}$ See also Deutsch (2009) on the Austrian social rented sector.
} 
conceptualization of housing systems is needed that encompasses all tenures. Van der Heijden et al. (2011) have contributed to this by adding a distinction between static and dynamic housing markets, pointing to the importance of the economic structure (labour market, labour mobility, structure and size of the financial sector, and so on). In part, such additional classifications boil down again to welfare regimes, but in relation to IH it is important to note that Van der Heijden et al. show that static housing systems tend to be characterized by a low number of transactions in the ownership market, and a high share of privately commissioned housing in new construction. This means that a substantial part of the development process is initiated and controlled by future owner-occupiers, using land which they acquire themselves. This limits the scope for IH, which presupposes the role of commercial developers. Therefore we may expect less interest in IH measures in countries with a static housing market. ${ }^{4}$

In this special issue we will take Kemeny's classification in combination with the notion of dynamic or static housing markets as a starting point-although not uncritically, for reasons said above-for understanding the role of housing systems in the institutionalisation of inclusionary housing.

\section{Planning systems}

In many countries, inclusionary housing has emerged as a response to problems experienced with the provision of social or affordable housing. But the extent to which it can be, and is, used differs greatly between countries. Inclusionary housing is a matter not only of affordability and housing need - the core concern of housing policy. Rather it involves the principles and mechanisms related to land and property rights. Like any institution, it has not only an instrumental value but also a symbolic one. In some countries, it is heavily contested because of its interference with property rights, while in others it passes without much opposition. Some consider inclusionary housing as a means to capture land value so as to redistribute wealth (Calavita and Mallach 2010), others as implicit taxation (Oxley 2008) or as 'regulatory taking' (Alterman 2010). The way inclusionary housing is discussed bears heavily on planning traditions and planning systems, which in their turn find their origin in property regimes. With regard to the value capturing capacity of planning systems, the countries featuring in this special issue cover the full range of the four land value recapture models that have been identified by Calavita and Mallach (2010, p. 361):

- Countries with explicit and extensive recapture mechanisms (England)

- Countries with explicit but limited recapture (Netherlands)

- Countries where recapture is implicit or ambiguous (Italy, Turkey)

- Countries where value recapture has not been, or is no longer, part of the planning culture (US, Australia, NZ, Norway).

Planning systems are also commonly divided into those that leave room for discretion at the stage of development control and those that do not and which, consequently, provide more legal certainty (see e.g. Booth 1996; Moroni 2007). In the UK, for instance, the local development plan is a legal requirement if certain policies are to be implemented. However while there is a presumption in favour of specified development, designations within the plan are not legally binding, which implies that if 'material considerations' suggest

\footnotetext{
${ }^{4}$ In their comparison of five countries Van der Heijden et al. (2011) classify Belgium and Germany as static housing markets, the UK and the Netherlands as dynamic markets, with Ireland in an intermediate position.
} 


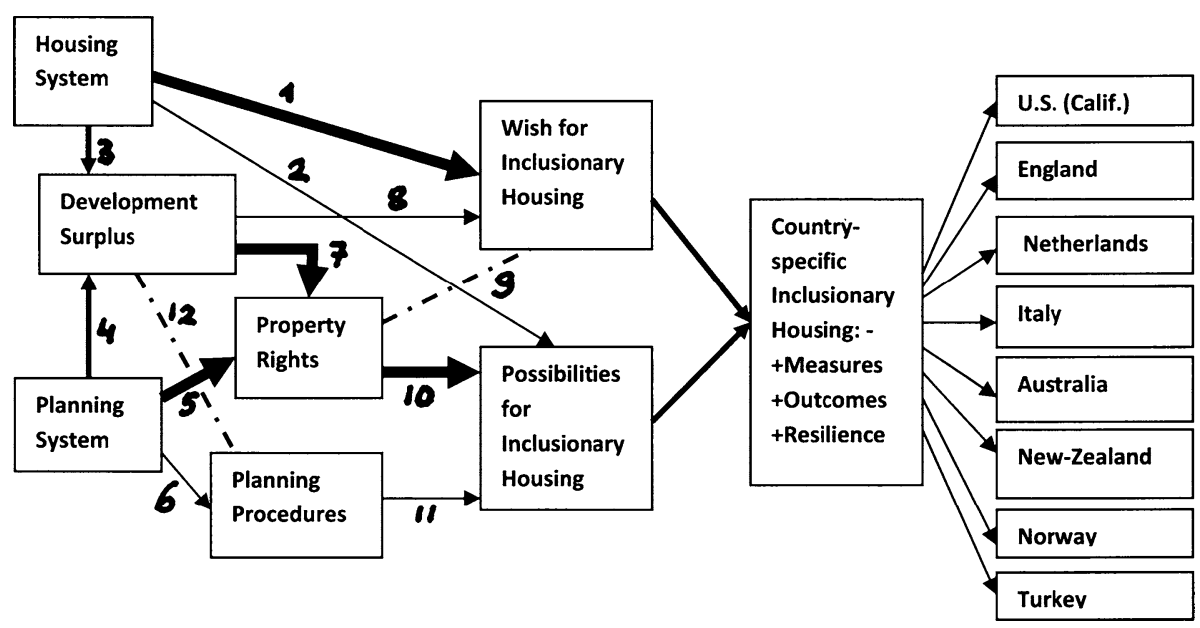

Fig. 2 Detailed model of the relations between housing and planning systems and inclusionary housing

deviation from the plan there is room for this to happen. In the Dutch case, on the other hand, there is a limited and known number of legally binding conditions in the land-use plan. If a building application complies with these conditions, permission has to be granted, if not, it has to be refused. It has been noted before that the dividing line between discretionary systems and systems that aim for legal certainty is not as strict as often argued (Moroni 2007; Buitelaar et al. 2011; Monk et al. 2013). In the Dutch case, for instance, the land-use plan is often revised to accommodate development initiatives, whereas Janssen-Jansen and Woltjer (2010) describe a tendency towards more plan-led development in the UK. ${ }^{5}$ The relevance of the distinction between discretion and certainty in the planning system is that a discretionary system gives the planning authority more power to negotiate with a commercial developer about the provision of social housing.

The third aspect of a planning system which influences the possibility of using IH is whether the application for a building permit on a particular location can legally be refused if the application is not for building (at least some) social housing. If this power is not available, then the wish of the planning authority to ensure that social housing is built in a particular location (which can include the wish for mixed tenures) can be frustrated by a commercial developer who does not wish to do so.

\section{Expectations about the relation between IH and the housing and planning systems}

Based on the above analysis of the ways in which housing and planning systems may affect the wish and possibility of $\mathrm{IH}$, and using a the more detailed model of these relations set out in Fig. 2, we put forward the following expectations about how both systems might affect IH policies. For that, we refer to the relationship between the elements of our

\footnotetext{
5 More generally, the distinction between the two types of development control is in many cases, but not necessarily, related to a distinction between common law and statutory law. In statutory legal systems, such as in the Germanic and Napoleonic legal families (Zweigert and Kötz 1977), law is constructed deductively, up-front, while in common law systems, such as in the UK, laws evolve incrementally through case decisions. Therefore, Salet (2002) speaks of deductive and inductive systems.
} 
conceptual model, as indicated by arrows and their corresponding numbers. The thickness of the arrows reflects the expected relative importance of these relationships, whereas dashed lines point at an indirect relationship. First we look at the wish to introduce IH.

Here we expect a strong relationship with the housing system (\#1) which includes the possibilities for providing social housing. If the possibilities without using $\mathrm{IH}$ are good, and if they have worked well in the past performance (sufficient numbers of social housing built, segregation or integration, etc.), the wish to introduce IH policies will be low.

Rather IH will be considered if there is a significant shortage of affordable housing in certain locations, and when the absence of that housing in those locations causes problems which are seen to be important. That can be a functional problem (e.g. insufficient labour for essential functions) or a social problem (e.g. undesirable segregation, or that low income households have access to much poorer facilities than high income households, or even social exclusion). If the scale of development is small (e.g. in small towns), and if affordable housing is available elsewhere in the town, then inclusionary zoning might not be considered necessary, for the occupants of that housing will have easy access to all work and facilities in the town. The availability of affordable housing depends in any case on the amount of that housing built in the past, and on how and where it has been built, also whether that housing is still available and has been protected from gentrification or redevelopment. Another link with the housing system is that ways of tackling the problems other than by inclusionary housing must be more difficult, less effective, less attractive or less acceptable in the local (political) culture, or more expensive.

Using the categories of housing systems given above, we would expect that the wish to introduce IH will be stronger (or come up earlier) in dualist as compared to unitary housing systems. The reason is that in dualist systems, affordable housing is likely to be more segregated and politicians are less likely to want to finance it to a good standard. Also, for reasons explained above, we might see $\mathrm{IH}$ more often in a dynamic than in a static housing market.

We expect an indirect relationship between the wish to introduce $\mathrm{IH}$ and the regulation of property, and more specifically development, rights in the planning system (\#9). If the planning system does not allow the owner of land to be restricted in detail (types of housing) in the way in which he or she may develop the land, then commercial developers cannot be restrained from building big estates of exclusively market housing. If this results in strongly segregated housing development, or in social housing at substandard locations, that may inspire the wish for IH.

Something else which might affect, indirectly, the wish to introduce IH is the size of the development surplus (\#8). This is the result of the interaction between the housing and the planning systems (\#3, \#4), and is dependent also on the economic situation. The expectation is that, if there is a big development surplus available (and if this is not creamed off in other ways), there will be a wish to use some of that in order to reduce the payments out of the public purse for social housing.

Second, we look at the possibilities for introducing IH.

These possibilities are to a large extent shaped by how the planning system allocates property rights and development rights (\#5 and \#10). The planning system largely determines in which way and to what extent development gain can be claimed by developers and,-in combination with other mechanisms - which part (if any) of that gain will be (re)distributed towards the provision of affordable housing. Also, the public administration must be competent enough to specify the requirements for each development, and to implement them. 
More in detail, the planning system is crucial for the possibilities of implementing IH for several reasons, most of which can be seen as specific elaborations of the general conditions for capturing value increases in urban (re) development (Muñoz 2010). First, the planning system should allow for private parties to develop land for housing purposes and to claim at least part of the gain from that development, and for government to regulate this development. Second, there must be a mechanism within the planning system or by other means (such as binding contracts) which recognizes social or affordable housing as relevant categories, which can or must be made subject to planning decisions for the sake of the public interest. Third, the planning system must contain rules on how the linkage between market and social housing can be enforced and in which form the developers' contribution to IH can or must be materialized. Fourth, the planning system must define rules for the local planning process such as identifying when irreversible decisions and agreements are taken/convened, and the level of (local) discretion (\#6 and \#11). Given that the need for affordable housing varies between locations, a planning system might perform better in creating possibilities for $\mathrm{IH}$ if it is flexible enough to allow the requirement to be applied with discretion, rather than as a mandatory, standard condition).

Thus, we expect both that one of the most fundamental aspects of national planning systems (the division of property rights and development rights between private and public bodies) as well as the more practical aspects of local discretion and flexibility will help us understanding why IH policies emerge (if any), how they are implemented and their resilience to change. At a fundamental level, the contrast between the UK (with nationalised development rights) and for example the USA (with zoning approaches) is evident, also with respect to the discourse about value capture and its acceptance in society. At the practical/procedural level we expect that differences between plan-led and development-led planning systems may be relevant, because such differences determine how public and private parties (can) deal with uncertainty in the various stages of the planning process. This has consequences for the public acceptance of IH measures, particularly because too much inflexibility might endanger investment levels.

The housing system will also (but in a less direct way) influence the possibilities of introducing IH (\#2), and the way it can be implemented. A basic feature of housing systems, with strong cultural roots, is the attitude towards different tenures, and the way this is reflected in the composition of the housing stock. Another link with the housing system is that IH cannot be introduced without an appropriate definition of the types of housing and households that are eligible to benefit from it, and a discourse for specifying housing needs and housing related problems for which IH is expected to bring a solution. If IH requirements materialize in land or money, the housing system must be ready to enable or support the production and/or financing of social and affordable units: in most countries free land or an in lieu fee will not suffice for the market to produce social housing for eligible households. Further, the mandatory delivery of completed housing units is possible only when the housing system has, or can create, landlords that can manage these houses according to the policy goals, or when the housing system can arrange that low income households are able to finance the acquisition of the affordable units. Another important condition for the acceptance and societal support of $\mathrm{IH}$ is usually the capacity of the housing system to retain the benefits of IH for eligible households exclusively, for a reasonable number of years.

Because most national housing systems have a long history of developing specific institutions, we expect that there will be a strong disposition to choose $\mathrm{IH}$ measures that fit in or link to those existing institutions. For this reason we would expect that, if there is a unitary rental market, with a strong position for not-for-profit landlords, these latter will be 
actively involved in construction and development, and will enjoy societal trust as a 'natural' mechanism for solving the retention problem. In a dualist system, it might not be evident who would develop, and retention might require specific contracts.

As under the definition used here $\mathrm{IH}$ is, at least in part, financed by capturing value from private parties, the third element in the model that we highlight is the existence and size of the surplus which can be 'creamed off' in the form of land, or affordable units, or money 'in lieu' for affordable housing. The surplus arises where there is a difference between the price of the final output and the costs of inputs including the opportunity cost of land (i.e. its value in the next best use). It is thus created in the economic process of land allocation, development and housing production. It is affected by the housing system (\#3)—which may provide subsidies or boost housing prices with fiscal support-as well as by the planning system which helps determine the supply of land to housing and to other uses (\#4); by the costs of public amenities that are charged to development; by regulation on density, type of dwelling and standards; and by the rules relating to other land and property taxation.

How much of any surplus goes to affordable housing depends on how many other calls there are on the pot of potential surplus - and on the relative power of landowners and developers as compared to local and national government. Most importantly the value available to be captured depends on the extent to which a change to the primary use of the land-usually to mainly market housing-leads to higher demand for the land, and therefore higher prices and the extent of constraint in land allocation to these uses. Thus the more the planning system constrains market provision, the more the potential for affordable housing to be achieved from what is actually built (although the practical possibilities of extracting some of the surplus for IH will depend on many other factors too).

If affordable housing and other local services funded in this way are seen as high priority, there may be a link between the level of development surplus and the wish for IH (\#9): high surpluses 'tempt' public bodies to claim their part (as we have already noted). But far more crucial is the relation between development surpluses, transferred through the property rights regime of the planning system (\#7) and the possibilities of value capturing by means of IH (\#10). On top of that there are also several indirect relationships (\#12) between planning procedures as defined in the planning system and development surplus: for example can a contribution be re-negotiated when the market goes down? And a depressing effect of IH requirements on the general level of land prices in a jurisdictionas signalled by Crook and Monk (2011) — may only be expected if planning procedures do not change from day to day.

In the next section the country-specific contributions to this special issue will be introduced. By relating the IH policy instrument to housing policies, to planning systems, and to the specific challenges related to the housing stock in each country, the articles deepen the understanding of housing policy entanglement and the transferability of policy tools across countries. It would not be correct to use the information about the various countries to 'test' the correctness of the expectations made about the relationships between $\mathrm{IH}$ and the housing and planning systems. The reason is that the expectations were derived not only deductively but also inductively, actively using the information about the different countries. What we have provided, is a theoretical model and expectations of how it works, and we invite others to examine it critically and to apply it to IH in other countries too. In that way, understanding how IH is embedded in planning and housing systems can be improved: how it is justified, whether it is practiced or not, and in what form. 


\section{Contributions from the different countries}

Authors from different countries across the spectre of housing and planning systems have contributed to this special issue. Although not written to a common format, they all explore how IH policies, and the devolution (or in some cases the absence) of such policies are embedded in their national housing and planning systems. The countries have been ranged according to the length of their experience with inclusionary housing: first the USA (California), then the UK, the Netherlands, Italy, Australia and New-Zealand, and finally Norway and Turkey.

The contribution of Wiener and Barton explores the causes of the rapid expansion of IH programmes in California, which has become the center of IH practice. During the last three decades, high population growth and home prices, dwindling land supplies, and State mandates that cities and counties meet their fair share of the affordable housing need, have prompted more than $25 \%$ (144) of the state's localities to adopt IH. These policies vary greatly in detail, but share common characteristics. Since 2007, however, the implosion of the housing market and the continuing economic recession have challenged the assumptions underlying inclusionary housing, causing governments to reconsider their policies. In addition, in California, two recent court cases have limited the power of localities to impose inclusionary rental restrictions, as well as fees in lieu of development. Today, one can reasonably ask whether California is now in a post-inclusionary period, in which the economic rationales and legal bases undergirding IH have been irretrievably altered. Without greater judicial clarity or new state legislation, will local governments modify their existing IH policies to meet these new conditions, temporarily suspend them, or repeal them? Will they seek affordable housing by alternative means, using other land use tools at their disposal? The authors discuss the justifications that gave rise to IH in California, the ideological, political, and economic undercurrents that inform the IH debate in the U.S., and the characteristics of these programs. They conclude with reflections on the market and legal challenges to implementation that inclusionary programs currently face in the State, and the implications for a post-inclusionary regime.

Recent developments in the UK are analysed by Morrison and Burgess. They demonstrate how more than 20 years of experience with inclusionary housing under Section 106 (S106) of the English 1990 Town and Country Planning Act have produced substantial completions of affordable units. This has been predicated on rising land values and market demand, which have enabled developers to agree and fulfill their planning obligations. The article explores how negotiations between local authorities and developers with regard to meeting S106 have altered during the economic downturn in England. Drawing on recent empirical research, and through the use of case studies, the article highlights the ways in which S106 agreements have been renegotiated at the site level, with the discretionary nature of the planning system allowing compromises to be made. Although S106 is linked to the state of the market, with developer contributions being reduced in a downturn, it has been an important policy tool in securing affordable housing and achieving inclusionary housing goals within England to date.

In an international comparative perspective, the Netherlands was relatively late in introducing Inclusionary Housing (Buitelaar and de Kam 2012). Applying a conceptual framework of the institutionalization of planning regulations, De Kam links this late introduction, as well as the specific content, and the actual use of $\mathrm{IH}$ measures to the context of the Dutch housing and planning system. In the Netherlands, the legal 'package' that in 2008 explicitly introduced the powers for local authorities to require IH (both for social/affordable housing and-a unique feature of the Dutch rules-also for privately 
commissioned housing) was strongly tied to new rules for cost recovery. The article uses information, from a review of existing empirical studies, of the use made of these different elements of the Dutch IH measures. The article uses also empirical data from a large survey of strategic choices made by housing associations in the land market. The paper shows that local authorities do use the new legal opportunity to put IH percentages in their land-use plans, but that there is a relatively low actual use of IH requirements 'with a bite' in the Netherlands. This outcome-which can be well explained by institutional factorsmay erode societal support for the IH policy. On the other hand, the institutional design of the rules is well attuned to existing path-dependent local policies which still deliver substantial numbers of new social and affordable housing. In these practices, value capturing is partly internalized in the operations of housing associations which develop mixed projects of social and commercial housing. In this respect, the real test of IH measures in the Netherlands is yet to come, depending on the resilience of (other) tried and trusted practices for providing social housing.

The article by Austin, Gurran and Whitehead also looks at IH in the UK, but from a different angle. It compares the English approach with those found in Australia and New Zealand, and tries to explain how such obviously divergent pathways can evolve from a similar legal framework. While all three nations began with a common starting pointearly British town planning legislation-underlying differences in urban regulation, property rights and housing provision soon emerged. However, signs of convergence have lately re-appeared, as all three countries have responded to affordable housing shortages by exploring new strategies to boost supply through the planning system. In the tradition of comparative housing research, this article examines these strategies in the context of each country's particular historical, socio-cultural, governance and urban planning frameworks. The analysis shows how variations in planning systems and in approaches to housing assistance can lead to different opportunities to provide affordable homes. Effective delivery of affordable housing through the planning system depends on consistent and enforceable policy articulation, government commitment, a mature affordable housing sector, and particular market conditions.

In her article on IH in Italy, Pogliani takes us to different local jurisdictions where various (rudimentary) forms of $\mathrm{IH}$ policies are being tested in urban land management schemes. The provision of social and affordable housing is a crucial objective in current Italian debate and literature. In the absence of national guidelines, cities and towns in Italy are experimenting with various ways of using planning instruments and housing policies. IH programs are playing an increasing role in local plans. They work through the negotiation process and the compensation approach, through competitive tenders and bonus incentives, as well as through more innovative devices such as 'perequazione' (equalisation via transferable development rights and land re-adjustment). The results are difficult to compare, mainly because the programmes arise from different objectives and welfare policies. Nevertheless they share both the abandonment of the expropriation mechanism as a tool to acquire land for social housing, and a serious commitment to create a social mix in new developments. Although the primary purpose is to build social and affordable units, in some cases land value recapture too has been an aim. The article explains and explores the quantitative and qualitative outcomes of the on-going IH programs, pointing to their different characters under different regional laws and local rules. The underlying question is the extent to which such programs meet the public and private needs in the supply of housing.

Norway is a country where IH policies are being considered, but have not yet been introduced. In her article, Nordahl conceptualises IH as a way to bring together housing 
supply policies and social housing policies, contrasting this to a situation where the two policies are kept separate. While countries with very different housing policies and different housing histories find a common ground in linking planning, general housing supply and affordable house measures, this linkage appears almost taboo in Norway's national housing policy document. Norway liberalised its housing policy in the late 1980-ies and has since then practised a marked-based housing policy. The question is whether the constitutional and organisational configurations that the last 25 years have been tailored to accommodate a liberal housing policy, incapacitate inclusionary housing policy. Drawing on theories of institutional change, the article highlights constitutional, organizational and cultural aspects of inclusionary housing policy, and compares this with the features of a policy where inclusionary housing has not been adopted. The article assesses similarities and differences between the English version of inclusionary housing and Norway's liberal housing and planning policy, where welfare considerations do not play a role in housing supply policies. The author concludes that if Norway wanted to implement inclusionary housing, it would be possible to adopt the current planning practices and finance schemes, but new organizations would have to be established. There are also cultural differences between the policy regimes that must be addressed.

In their article on Turkey, Turk and Korthals Altes examine the prospects for IH policies in Turkey, which is characterised not only by a dualist rental market but also by the existence of large-scale illegal markets, with almost $30 \%$ of the urban population living in squatter dwellings. They demonstrate that, in the typical dual structure of both legal and illegal land development, the legal sector is not able to provide land for housing development for the poor and middle-income population. A traditional role of government as regulator, in Turkey based on Reconstruction Law, does not change this. The government has taken on, in addition to its role as regulator, the role of investor. The article examines the applicability of inclusionary housing in legal and illegal segments of the housing market. In addition, it asks whether land readjustment (LR) schemes, which are much used in Turkey, could be used for $\mathrm{IH}$, and what legal changes would be necessary for that.

Acknowledgments The authors thank Christine Whitehead for her comments on an earlier version of this editorial.

\section{References}

Alterman, R. (2010). Takings international: A comparative perspective on land use regulations and compensation rights. Chicago: ABA.

Ball, M. (1983). Housing policy and economic power:the political economy of owner occupation. London: Routledge.

Ball, M. (1998). Institutions in British property research: A review. Urban Studies, 35(9), 1501-1517.

Bengtsson, B., \& Ruonavaara, H. (2010). Introduction to special issue: Path dependence in housing. Housing, Theory and Society, 27(3), 193-203.

Blessing, A. (2012). Magical or monstrous? Hybridity in social housing governance. Housing Studies, 27(2), 189-207.

Booth, P. (1996). Controlling development: Certainty and discretion in Europe, the USA and Hong Kong. London: UCL Press.

Buitelaar, E., \& de Kam, G. (2012). The emergence of inclusionary housing: Continuity and change in the provision of land for social housing in the Netherlands. Housing, Theory and Society, 29(1), 56-74.

Buitelaar, E., Galle, M., \& Sorel, N. (2011). Plan-led planning systems in development-led practices: An empirical analysis into the (lack of) institutionalisation of planning law. Environment and Planning A, 43, 928-941. 
Calavita, N., \& Grimes, K. (1998). Inclusionary housing in California. Journal of the American Planning Association, 64(2), 150-169.

Calavita, N., Grimes, K., \& Mallach, A. (1997). Inclusionary housing in California and New Jersey: A comparative analysis. Housing Policy Debate, 8(1), 109-142.

Calavita, N., \& Mallach, A. (2009). Inclusionary housing, incentives and land value recapture. Land lines, 21(January), 15-21.

Calavita, N., \& Mallach, A. (2010). Inclusionary housing in international perspective: Affordable housing, social inclusion, and land value recapture. Cambridge, MA: Lincoln Institute of Land Policy.

Crook, A., \& Monk, S. (2011). Planning gains, providing homes. Housing Studies, 26(7-8), 997-1018.

Deutsch, E. (2009). The Austrian social rented sector at the crossroads for housing choice. International Journal of Housing Policy, 9(3), 285-311.

Esping-Andersen, G. (1990). The three worlds of welfare capitalism. Cambridge: Polity Press.

Glaeser, E. L., Gyourko, J., \& Saks, R. (2005). Why is Manhattan so expensive?: Regulation and the rise in house prices. Journal of Law and Economics, 48(2), 331-370.

Harloe, M. (1995). The people's home?: Social rented housing in Europe \& America. Oxford, UK: Blackwell.

Hoekstra, J. (2009). Two types of rental system? An exploratory empirical test of Kemeny's rental system typology. Urban Studies, 46(1), 45-62.

Janssen-Jansen, L., \& Woltjer, J. (2010). British discretion in Dutch planning: Establishing a comparative perspective for regional planning and local development in the Netherlands and the United Kingdom. Land Use Policy, 27(2), 906-918.

Kemeny, J. (2001). Comparative housing and welfare: Theorising the relationship. Journal of Housing and the Built Environment, 16, 53-70.

Monk, S., Burgess, G., Tang, C., \& Whitehead, C. (2013). International review of land supply and planning systems. York: Joseph Rowntree Foundation.

Monk, S., \& Whitehead, C. (2010). Making housing more affordable. Oxford: Wiley Blackwell.

Mallach, A. (1984). Inclusionary housing programs: Policies and practices. New Brunswick, NJ: Center for Urban Policy Research.

Monk, S., Whitehead, C. \& Burgess, G. (2007). The provision of affordable housing through section 106: The situation in 2007. RICS Research paper series, 14(7). London: RICS.

Moroni, S. (2007). Planning, liberty and the rule of law. Planning Theory, 6(2), 146-163.

Muñoz, D. (2010). Capturing value increase in urban redevelopment. Leiden:Sidestone Press

Needham, B. (2012). Institutions for housing supply. In D. J. Smith, M. Elsinga, L. Fox, O. O’Mahony, S. Seow Eng, \& S. Wachter (Eds.), International encyclopedia of housing and home (pp. 99-108). Oxford: Elsevier.

Oxley, M. (2004). Economics, planning and housing. London: Palgrave Macmillan.

Oxley, M. (2008). Implicit land taxation and affordable housing provision in England. Housing Studies, 23(4), 661-671.

Quigley, J. M., \& Raphael, S. (2005). Regulation and the high cost of housing in California. American Economic Review, 95(2), 323-328.

Salamon, L., \& Lester, M. (1997). Defining the nonprofit sector: A cross-national analysis. Manchester: Manchester University Press.

Salet, W. G. M. (2002). Evolving institutions: An international exploration into planning and law. Journal of Planning Education and Research, 22, 26-35.

Van der Heijden, H., Dol, K., \& Oxley, M. (2011). Western European housing systems and the impact of the international financial crisis. Journal of Housing and the Built Environment, 26(3), 295-313.

Williams, P. (2000). Inclusionary zoning and affordable housing in Sydney. Urban Policy and Research, 18(3), 291-310.

Zweigert, K., \& Kötz, H. (1977). An introduction to comparative law. Amsterdam: Elsevier. 